

\section{Leader influence}

Leadership can also be paternalistic, but in general when it comes to leadership models they are considered as either hierarchical ${ }^{5}$ or flat $^{5}$ and either task-oriented or relationshiporientated. Commonly identified as being task-orientated is associated with goal accomplishment and relationship-orientated is more about helping followers feel better about situations, themselves, and others.

When focusing on leadership types, the following list is helpful but not exhaustive: ${ }^{8}$

- Transformational

- Transactional

Invitational

- Situational

authentic

Distributed

Adaptive

- Team

- Servant.

A further consideration is the difference between appointed leadership and emergent leadership and the plethora of theories surrounding leadership ie contingency theory and path-goal theory. The conceptual skills of leadership are identified as problem solving, strategic planning and creating vision. Whichever skill is being applied there is great benefit in establishing ethical leadership practice; ${ }^{9}$ notably as a General Dental Council registrant this should be a given.

Like any field there are common mistakes made and they are worth considering: 5

- Not sharing a common vision

- Failing to define goals

- Not delegating

- Misunderstanding motivation

Failing to provide feedback

Not 'walking the walk'

Not making time for your team

Being too hands-off

Being too friendly

A mismatch of approach and situation

Not considering the infrastructure of the group.

Adapted from Mindtools $2021^{10}$

In this paper there has been some focus on the leaders themselves and although it is beyond its remit to unpick this component more, it is worth investigating.

In conclusion, I go back to the smallscale research undertaken in 2016 as part of a Master's programme: leadership can be part of any team member's role no matter what to which registrable group they belong or what their role is. A word of warning is not to confuse leadership and management, we know now there are distinct differences.

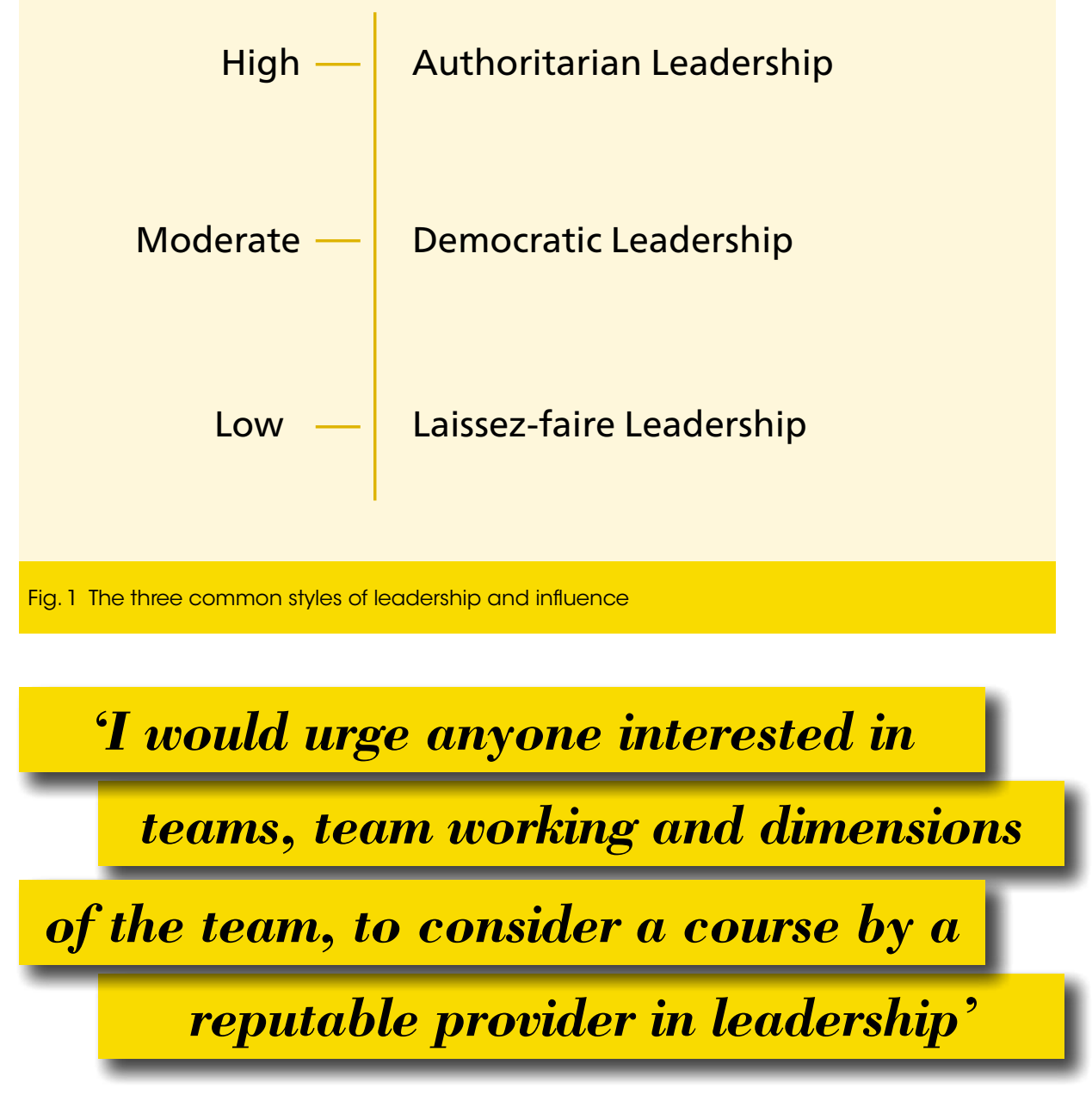

Creating a leadership culture is essential for a sustainable future in dentistry. ${ }^{11}$ I would urge anyone interested in teams, team working and dimensions of the team, to consider a course by a reputable provider and awarding body in leadership, you may well make very different decisions as a result of this.

\section{References}

1. Ellwood F. Building leadership capacity. Presentation. East Midlands: Dental Nurses Annual Conference, 2018.

2. Kotter J P. Leading change. USA: Harvard Business Review Press, 2012.

3. Hesburgh T. 'The very essence of leadership is that you have vision. You can't blow an uncertain trumpet.' 1917. In Andrews J F, Covell J A. Preparing future teachers and doctoral-level leaders in deaf education: meeting the challenge. Am Ann Deaf 20062007; 151: 464-475.

4. Brocklehurst P, Ferguson J, Taylor N, Tickle $\mathrm{M}$. What is clinical leadership and why might it be important in dentistry? Br Dent J 2012; 214: 243-246.

5. Northouse P G. Leadership: theory and practice. 9th edition. London: Sage, 2021.

6. Azad N, Anderson H G Jr, Brookes A et al.
Leadership and management are one and the same. Am J Pharm Educ 2017; doi: 10.5688/ ajpe816102.

7. Easley S. The relationship between leadership style and personality type among college students. Honors Theses 2019; https:// doi.org/10.33015/dominican.edu/2019. HONORS.ST.16. Available at: https:// scholar.dominican.edu/cgi/viewcontent. cgi? article $=1059 \&$ context=honors-theses (accessed January 2022).

8. Outhwaite D. Education with a personal touch. Presentation. 2006.

9. Skelton J. Leadership in Primary Dental Care Presentation. East Midlands: HEE Foundation dentists workshop, 2003.

10. MindTools. 10 Common Leadership and Management Mistakes. Avoiding Universal Pitfalls. Available at: https://www.mindtools. com/pages/article/leadership-mistakes.htm (accessed December 2021).

11. Metwally D, Ruiz-Palomino P, Metwally M, Gartzia L (2019) How ethical leadership shapes employees' readiness to change: the mediating role of an organizational culture of effectiveness. Front Psychol 2019; doi: 10.3389/fpsyg.2019.02493. https://doi.org/10.1038/s41407-022-0828-8: 